Supporting Information

\title{
Solid State Dilution Controls Marcus Inverted Transport in Rectifying Molecular Junctions
}

\author{
Hungu Kang, " Gyu Don Kong, ${ }^{\text {a }}$ and Hyo Jae Yoon * \\ Department of Chemistry, Korea University, Seoul 02841, Korea \\ Corresponding author’s email: hyoon@korea.ac.kr (H.J.Y.). \\ \#These authors equally contribute to this work.
}




\section{$\underline{\text { Table of Contents }}$}

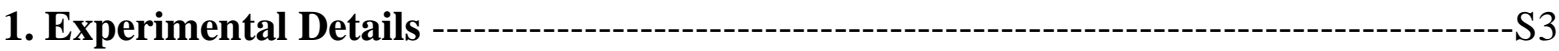

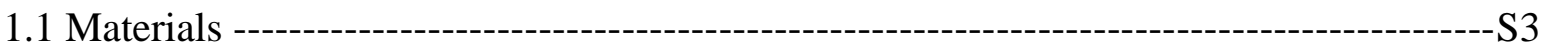

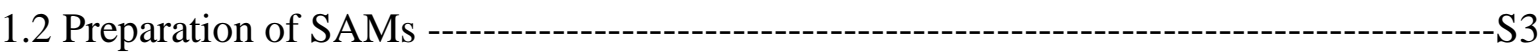

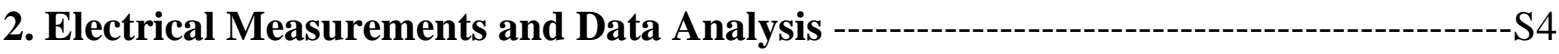

2.1 Preparation of EGaIn Tethered Tip -------------------------------------------------------S4

2.2 Preparation of Untethered EGaIn Junction -----------------------------------------S4

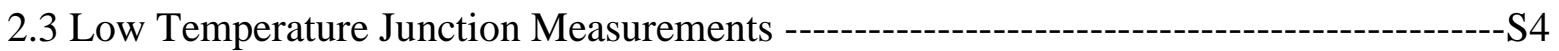

2.4 Electrical Measurements and Data Analysis --------------------------------------------------S5

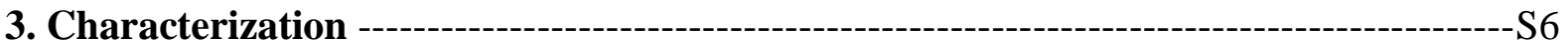

3.1 X-ray Photoelectron Spectroscopy (XPS) Measurements ------------------------------------S6

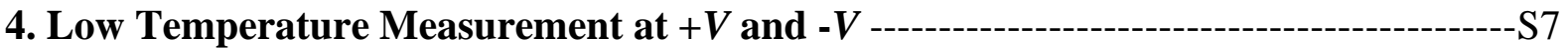

5. Minor Discussion ---

6. Contact Angle Measurement ---

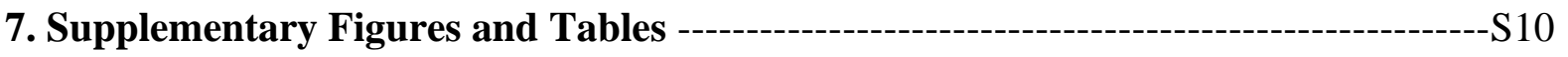

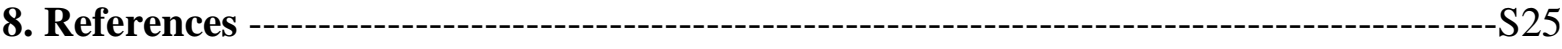




\section{Experimental Details}

\subsection{Materials}

All reagents were used as supplied unless otherwise specified. All organic solvents were purchased from Sigma-Aldrich and Daejung while water was purified using an Aqua MAX-Basic System (deionized water, the electrical resistivity of which is $\sim 18.2 \mathrm{M} \Omega \cdot \mathrm{cm}$ ). High purity eutectic gallium-indium (EGaIn; 99.99\%) was obtained from Sigma-Aldrich and used as supplied. 2,2'-Bipyridyl-terminated $n$-undecanethiol $\left(\mathrm{BIPY}\left(\mathrm{CH}_{2}\right){ }_{11} \mathrm{SH}\right)$ was synthesized following the procedures reported in the literature. ${ }^{1}$ All thiol derivatives were stored under $\mathrm{N}_{2}$ atmosphere and $<4{ }^{\circ} \mathrm{C}$. Silver and gold thin films $(\sim 300 \mathrm{~nm})$ were deposited onto silicon wafer (100 $\mathrm{mm}$ in diameter; $1-10 \mathrm{ohm}-\mathrm{cm}, 525 \pm 50$ microns thick) by e-beam evaporator (ULVAC). For template-stripping and untethering of junction, photo-curable polymer was purchased from Norland (NOA81) and used as supplied.

\subsection{Preparation of SAMs}

We prepared SAMs following the procedure reported previously. ${ }^{2}$ Briefly, toluene (anhydrous, $99.9 \%$ ) solution (total concentration: $3 \mathrm{mM}$ ) containing $\mathrm{HSC}_{11} \mathrm{BIPY}$ was added to a vial. The solution was sealed and degassed by bubbling $\mathrm{N}_{2}$ through the solution for $c a$. $10 \mathrm{~min}$. Template-stripped metal substrates were prepared following the procedure reported previously. ${ }^{3} \mathrm{~A}$ freshly prepared $\mathrm{Au}^{\mathrm{TS}}$ chip was rinsed with pure toluene, and placed to the solution with the exposed metal face up. The vial was then filled with $\mathrm{N}_{2}$. After $3 \mathrm{~h}$ incubation at room temperature, the SAM-bound $\mathrm{Au}^{\mathrm{TS}}$ chip was removed from the solution and rinsed by repeatedly dipping the chip into clean toluene $(3 \times 1 \mathrm{~mL})$. The solvent on the SAM was then evaporated in air for a few seconds. 


\section{Electrical Measurements and Data Analysis}

\subsection{Preparation of EGaIn Tethered Tip}

A conical tip of EGaIn was formed following the method reported in the literature. ${ }^{4}$ Briefly, a $10 \mu \mathrm{L}$ gas-tight syringe was filled with EGaIn ( $\geq 99.99 \%$, Aldrich). A drop of EGaIn was pushed to the tip of the syringe needle, the hanging drop was brought into contact with a surface on which the EGaIn could stick (e.g., an oxidized Ag surface), and the needle gently pulled away from the drop using a micromanipulator. Upon breaking from the bulk EGaIn on the surface, a conical tip was obtained. A conical tip of EGaIn was newly formed every junction in order to eliminate complexities that may arise from contamination of the EGaIn surface by volatile organics in air. In cases that visible whiskers formed during tip fabrication, the tip was discarded, and a new tip was formed.

\subsection{Preparation of Untethered EGaIn Junction}

For low temperature experiments, EGaIn conical tip was untethered following the previously reported method. ${ }^{4}$ EGaIn conical tip was first prepared and brought to a surface of SAM for top-contact. A few microgram of photo-curable polymer was placed near the formed junction. Immediately the polymer overspread the junction, which could be confirmed by optical microscopy, we flooded it with ultraviolet (UV) light using a handheld lamp for few seconds. For untethering, the syringe was lifted up using a micromanipulator.

\subsection{Low Temperature Junction Measurements}

To measure of temperature dependent of $J(V)$, we biased the $\mathrm{Ga}_{2} \mathrm{O}_{3} / \mathrm{EGaIn}$ topelectrodes and grounded the $\mathrm{Au}^{\mathrm{TS}}$ bottom-electrode. The temperature dependent 
measurements were performed with a cryogenic probe station in vacuum $\left(1 \times 10^{-3} \mathrm{bar}\right)$. The devices were cooled with liquid nitrogen from 298 to $118 \mathrm{~K}$ over the course of two hours. At intervals of $10 \mathrm{~K}$, we contacted the $\mathrm{Au}^{\mathrm{TS}}$ and $\mathrm{Ga}_{2} \mathrm{O}_{3} / \mathrm{EGaIn}$ electrodes with the probes and recorded three $J(V)$ curves while keeping the temperature constant.

\subsection{Electrical Measurements and Data Analysis}

Junction formation and measurements were done following the method reported in the literature. ${ }^{1}$ All junction formation and measurements in this work were carried out in ambient conditions. Briefly, a SAM was gently brought into contact first with a gold metal electrode. Then using a micromanipulator, a conical tip of EGaIn was gently brought into contact with the surface of SAM. The SAM-bound bottom electrode was grounded, and the EGaIn top electrode was biased.

The diameter of the contact area was measured at high magnification. Assuming a circular contact, the area was derived from the measured diameter from which the current densities $\left(J, \mathrm{~A} / \mathrm{cm}^{2}\right)$ were calculated. The contact and presence of a SAM was confirmed by running a single $J-V$ scan after which 20 more scans were run if there was indication of contact and tunneling. A trace is based on the following voltage sweep sequence: $0 \mathrm{~V} \rightarrow$ $+1.0 \mathrm{~V} \rightarrow 0 \mathrm{~V} \rightarrow-1.0 \mathrm{~V} \rightarrow 0 \mathrm{~V}$. Therefore, one trace corresponds to two scans. The total number of working junctions versus those that shorted was used to calculate the yield (\%) of working junctions. Shorts have been usually excluded prior to analysis. Shorts clearly do not give information about the SAM and can bias distributions of current density toward high values. ${ }^{5}$ Thus, when one performs operations on the raw distribution of logcurrent density $(\log |J|)$, one discards values corresponding to shorts. Shorts are defined as values of current that reach the compliance limit of our electrometer $( \pm 0.105 \mathrm{~A})$. For 
generating histograms, we kept the bin-size of $r$ histograms constant, making the resolution of mean values (the width of each bean is $\sim 0.14$ in a log-scale).

\section{Characterization}

\subsection{X-ray Photoelectron Spectroscopy (XPS) Measurements}

The XPS measurements were carried out on a Thetaprobe (Thermo) with a monochromated Al Ka $(1486.6 \mathrm{eV})$ source. The measurements were done at room temperature in a vacuum of $6.7 \times 10^{-8} \mathrm{~Pa}$. The binding energies were calibrated by setting $\mathrm{Au} 4 \mathrm{f}_{7 / 2}$ of bulk metals to values $84.0 \mathrm{eV}$. The XPS N1s and S2p lines were detected to study the $\mathrm{SC}_{11} \mathrm{BIPY}$ SAM and consistent with the literature results. ${ }^{1-3}$ The peak shapes of the core level photoelectron spectra were analyzed with a XPS Peak Fit program. A Shirley-type background correction was utilized. The $S 2 p_{3 / 2}$ and $S 2 p_{1 / 2}$ lines were fitted with a fixed binding energy difference of $1.18 \mathrm{eV}$ and an intensity ratio of 2:1, reflecting the multiplicity of the $\mathbf{S} 2 \mathrm{p}_{3 / 2}$ and $\mathrm{S} 2 \mathrm{p}_{1 / 2}$ energy levels. ${ }^{6}$ The reproducibility of the data was confirmed by measuring the data in different samples. Since the addition of $\mathrm{SC}_{11} \mathrm{BIPY}$ essentially produced a detectable nitrogen signal in the SAMs, we estimated the values of $\chi_{S C n}^{\text {surf }}$ by comparing the N1s peak areas for different pure and mixed SAMs, as previously described. ${ }^{7}$ We avoided the use of C1s and S2p signals as references to eliminate complexities arising from the surface contamination of SAMs by adventitious airborne organic compounds and the different degrees of sulfur photoelectron attenuation by the alkyl backbones. ${ }^{7}$ 


\section{Low Temperature Measurement at $+V$ and $-V$}

Casual inspection of the Arrhenius plots in Figure S7-S8 suggests the slopes from room temperature to the crossover temperatures at $+V$ and $-V$ are seemingly similar. Accurate calculations of $E_{\mathrm{a}}$ values, however, indicate that the magnitude of $E_{\mathrm{a}}$ at $+V$ is overall larger than that at $-V$ : the values of $E_{\mathrm{a}}$ at $+V$ varied from 45 to $181 \mathrm{meV}$ whereas the values of $E_{\mathrm{a}}$ at $-V$ varied from 78 to $93 \mathrm{meV}$. In our junction platform, the $\mathrm{SAM}$-bound $\mathrm{Au}^{\mathrm{TS}}$ bottom electrode is grounded. At $+V$, the EGaIn top electrode is oxidizing, and at $-V$ this electrode is reducing. At $+V$, BIPY is reduced to form a radical anion $\left(\mathrm{BIPY}{ }^{\bullet-}\right)$. Note that it has been established through wet electrochemical analysis that one-electron reduction rather than oxidation preferentially occurs in 2,2'-bipyridine, and the difference in environments such as presence and absence of solvation and intermolecular packing effects can cause deviation in reduction potential between solid-state (the molecular junction) and solution phase (the wetelectrochemical experiments). ${ }^{1,8-9}$

\section{Minor Discussion}

The dilution-induced structural disorder of monolayers would contribute to the decrease in the rectification ratio. ${ }^{2}$ However, we believe the effect by structural disorder cannot account for our result. The degree of structural disorder of $\mathrm{SC}_{11} \mathrm{BIPY}$ usually increases as the difference in length between $\mathrm{SC}_{11} \mathrm{BIPY}$ and $\mathrm{SC}_{\mathrm{n}}$ is larger; when the degree of structural disorder increases, the yield of working junctions decreases. ${ }^{3,6}$ Our experiments revealed that the rectification ratio for dilution with the long molecule was indistinguishable from that for dilution with the short molecules (Figure 2b). There was no correlation between molecular dilution and the yield of working junctions: all the mixed SAMs exhibited similar and fairly high yields of working junctions (74-89\%) (Table S3 in the Supporting Information). 


\section{Contact Angle Measurement}

Static $\left(\cos \theta_{\mathrm{s}}\right)$ and dynamic $(\Delta \cos \theta)$ contact angle measurements permit access to distinct types of surface-structural information: the dominant surface-exposing group and the degree of structural defects, respectively. ${ }^{3}$ The Cassie law in Eq. S1 accounts for wettability

$$
\cos \theta=f_{1} \cos \theta_{1}+f_{2} \cos \theta_{2} \quad \text { Eq. S } 1
$$

behaviors on composite surfaces, where $f_{\mathrm{i}}$ and $\cos \theta_{\mathrm{i}}$ are the area fraction and the contact angle for component $i$, respectively, and $f_{1}+f_{2}=1 .{ }^{10}$ Figure S7 shows the data of contact angle measurements, and the straight black line indicates Casie prection expected by Eq. S1.

As the $\cos \theta_{\mathrm{s}}$ value is closer to the Cassie prediction, the monolayer is more homogeneously mixed. In case of the fixed surface mole fraction $\left(\chi_{S C n}^{\text {surf }}=0.3\right), \cos \theta_{\mathrm{s}}$ was slightly higher than the Cassie prediction (the straight black line), as shown in Figure S7-a,c,e. The fact that the $\cos \theta_{\mathrm{s}}$ value was higher than the Cassie prediction implies that BIPY was dominantly exposed to the surface due to the shorter length of $\mathrm{SC}_{n}$ (especially for $\mathrm{n}=8$ and 10 ) than $\mathrm{SC}_{11} \mathrm{BIPY}$. If the phase segregation were significant, the surface would be dominated by both BIPY and methyl groups. Therefore, the contact angle data indicates that heterogeneous mixing (i.e., phase segregation) of $\mathrm{SC}_{11} \mathrm{BIPY}$ and $\mathrm{SC}_{\mathrm{n}}$ molecules is not significant.

Value of $\Delta \cos \theta$ is intimately related to the molecular-level surface topography of organic surfaces. ${ }^{3}$ The surface chemical heterogeneity of mixed SAMs does not contribute to contact angle hysteresis. ${ }^{10}$ Thus, we assumed that our hysteresis $(\Delta \cos \theta)$ data contains primarily the information about the surface topography. If the measured value of $\Delta \cos \theta$ is higher than the values of the pure SAMs $\left(\chi_{\mathrm{SCn}}^{\mathrm{surf}}=0.0\right.$ and 1.0), the surface is heterogeneous and disordered. At the fixed surface mole fraction $\left(\chi_{S \mathrm{~S} n}^{\mathrm{surf}}=0.3\right)$, the measured values of $\Delta \cos \theta$ were similar or lower than the values of the pure SAMs as shown in Figure S7b,d,f. This 
finding further confirms that our SAMs did not undergo significant phase segregation and were not significantly disordered upon dilution, relative to the pure SAMs. 


\section{Supplementary Figures and Tables}

Figure S1. Energy diagram of $\mathrm{Au}^{\mathrm{TS}} / \mathrm{SC}_{11} \mathrm{BIPY} / / \mathrm{Ga}_{2} \mathrm{O}_{3} / \mathrm{EGaIn}$ junction. The HOMO of $\mathrm{Au}-\mathrm{S}$ moiety and the LUMO of BIPY are electronically decoupled from each other via the long $n$ alkyl spacer and pinned at the Fermi level of electrodes. It was taken from the ref 11.

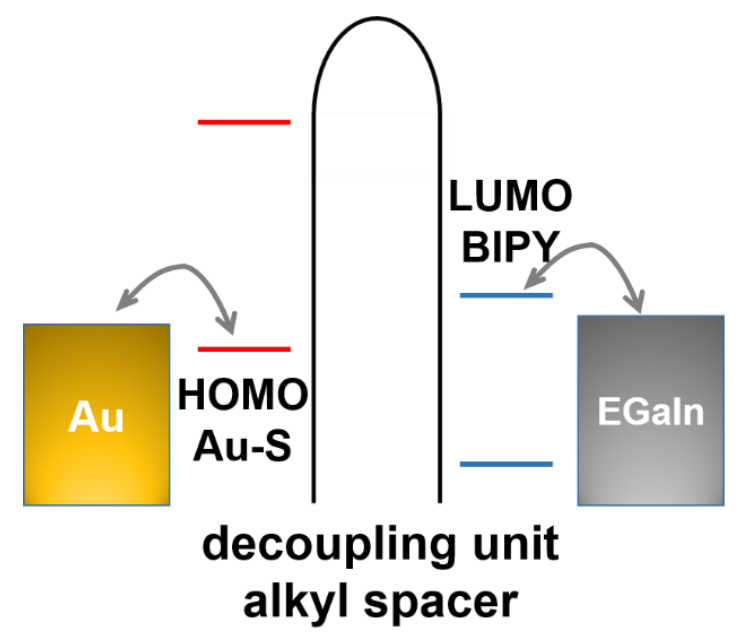


Figure S2. XPS survey spectra for (a) pure $\mathrm{SC}_{11} \mathrm{BIPY}$ SAM and (b-e) binary mixed SAMs $\left(\mathrm{SC}_{11} \mathrm{BIPY}+\mathrm{SC}_{\mathrm{n}}\right.$ where $\mathrm{n}=8,10$, or 18$)$ on $\mathrm{Au}^{\mathrm{TS}}$.

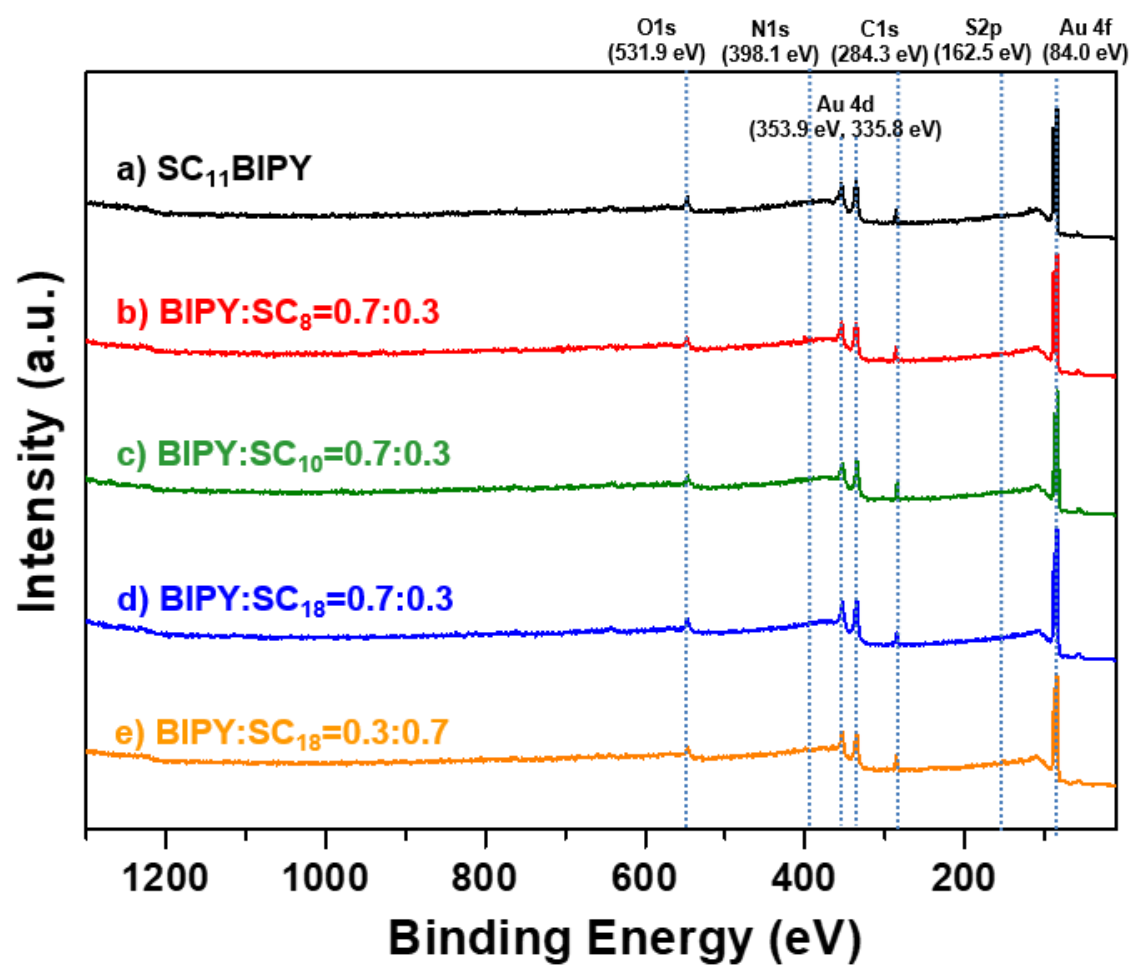


Figure S3. High resolution XPS spectra for S2p of pure $\mathrm{SC}_{11} \mathrm{BIPY}$ and binary mixed SAMs $\left(\mathrm{SC}_{11} \mathrm{BIPY}+\mathrm{SC}_{\mathrm{n}}\right.$ where $\mathrm{n}=8,10$, or 18$)$ on $\mathrm{Au}^{\mathrm{TS}}$.
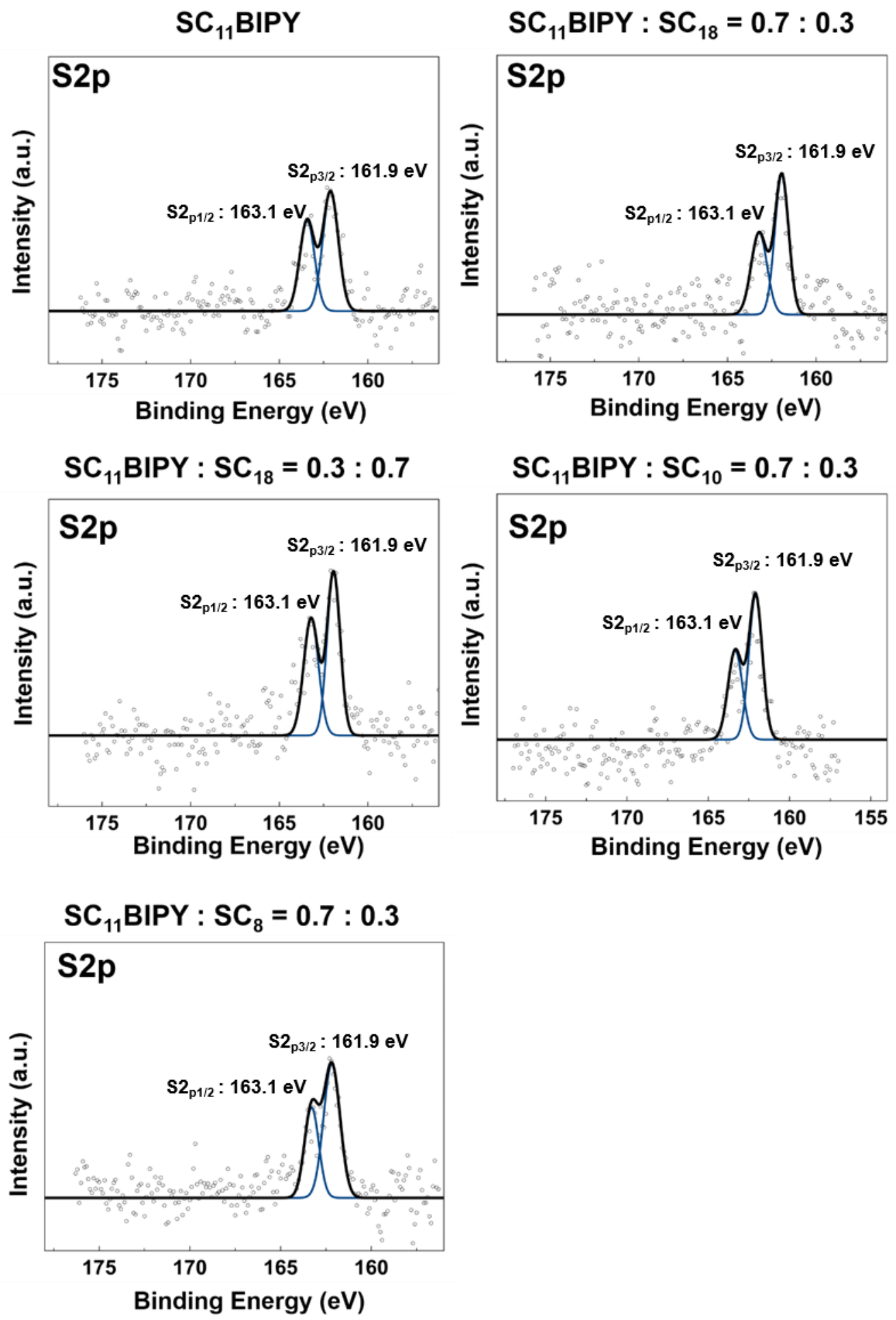
Figure S4. High resolution XPS spectra for N1s of a series of single-component and binary mixed SAMs formed with $\mathrm{SC}_{11} \mathrm{BIPY}$ and $\mathrm{SC}_{18}$ on $\mathrm{Au}^{\mathrm{TS}}$. Inset shows integrated areas of N1s peaks plotted against the mole fraction of $\mathrm{HSC}_{11} \mathrm{BIPY}$ in solution $\left(\chi_{\mathrm{HSC11BIPY}}^{\mathrm{soln}}\right)$.

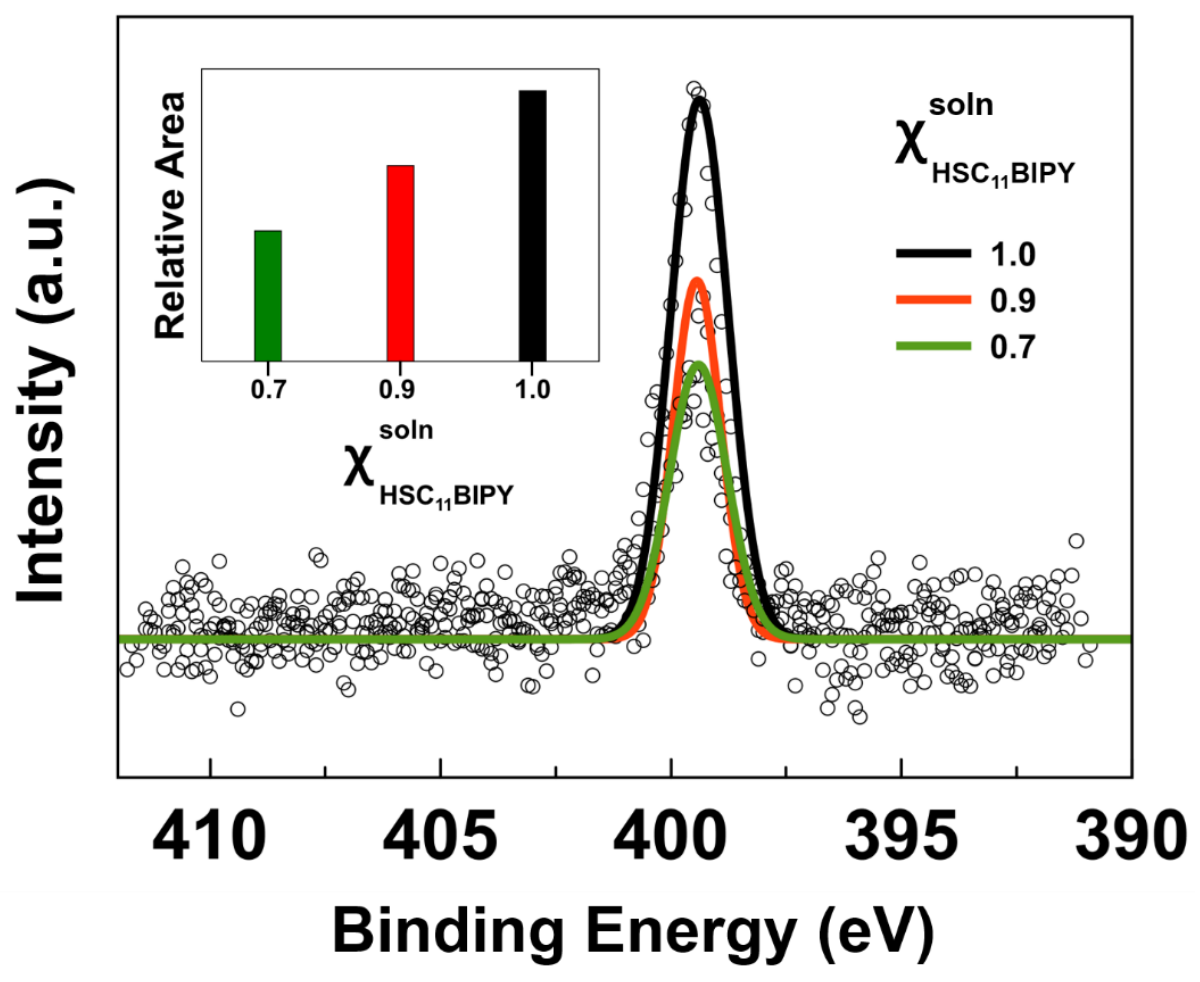


Figure S5. High resolution XPS spectra for N1s of a series of single-component and binary mixed SAMs formed with $\mathrm{SC}_{11} \mathrm{BIPY}$ and $\mathrm{SC}_{10}$ on $\mathrm{Au}^{\mathrm{TS}}$. Inset shows integrated areas of N1s peaks plotted against the mole fraction of $\mathrm{HSC}_{11} \mathrm{BIPY}$ in solution $\left(\chi_{\mathrm{HSC11BIPY}}^{\mathrm{soln}}\right)$.

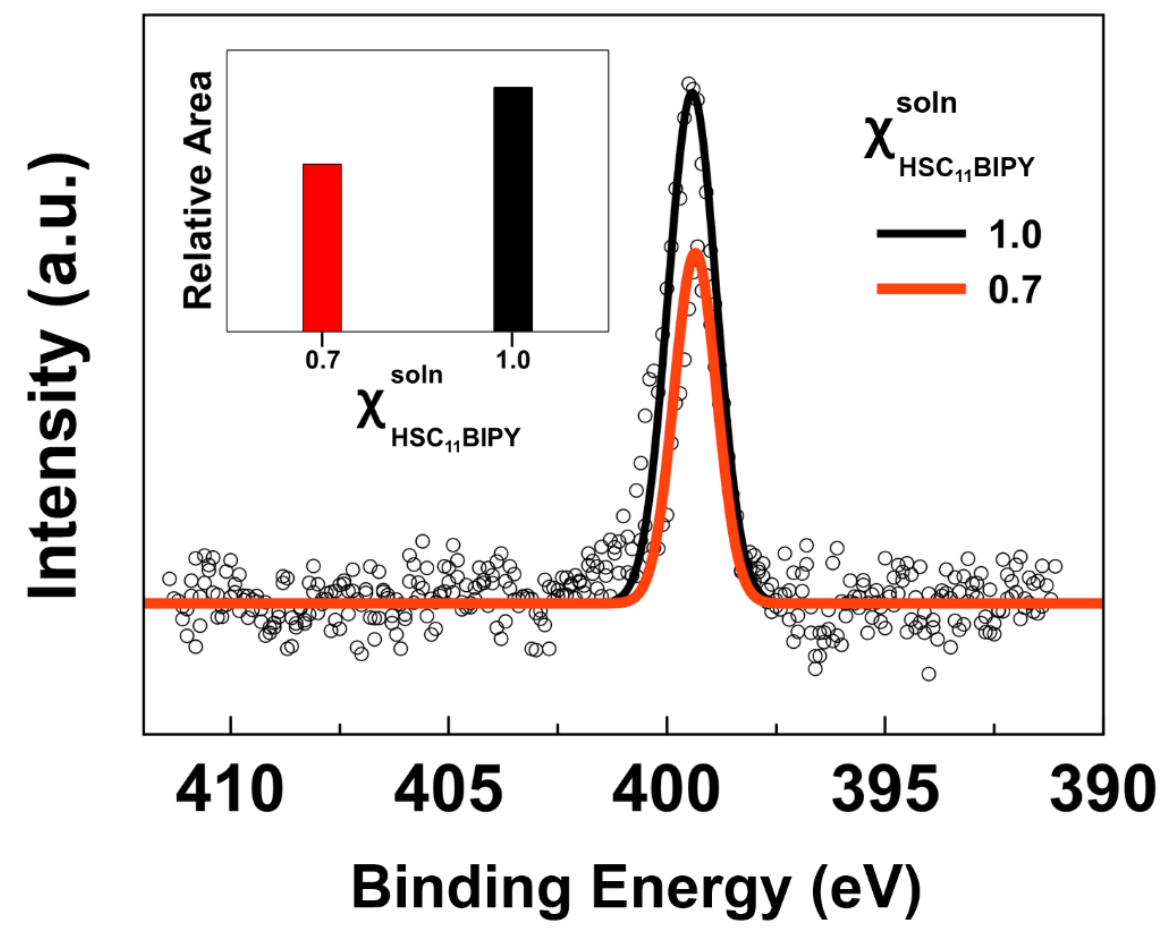


Figure S6. High resolution XPS spectra for N1s of single-component and binary mixed SAMs formed with $\mathrm{SC}_{11} \mathrm{BIPY}$ and $\mathrm{SC}_{8}$ on $\mathrm{Au}^{\mathrm{TS}}$. Inset shows integrated areas of N1s peaks plotted against the mole fraction of $\mathrm{HSC}_{11} \mathrm{BIPY}$ in solution $\left(\chi_{\mathrm{HSC11BIPY}}^{\mathrm{soln}}\right)$.

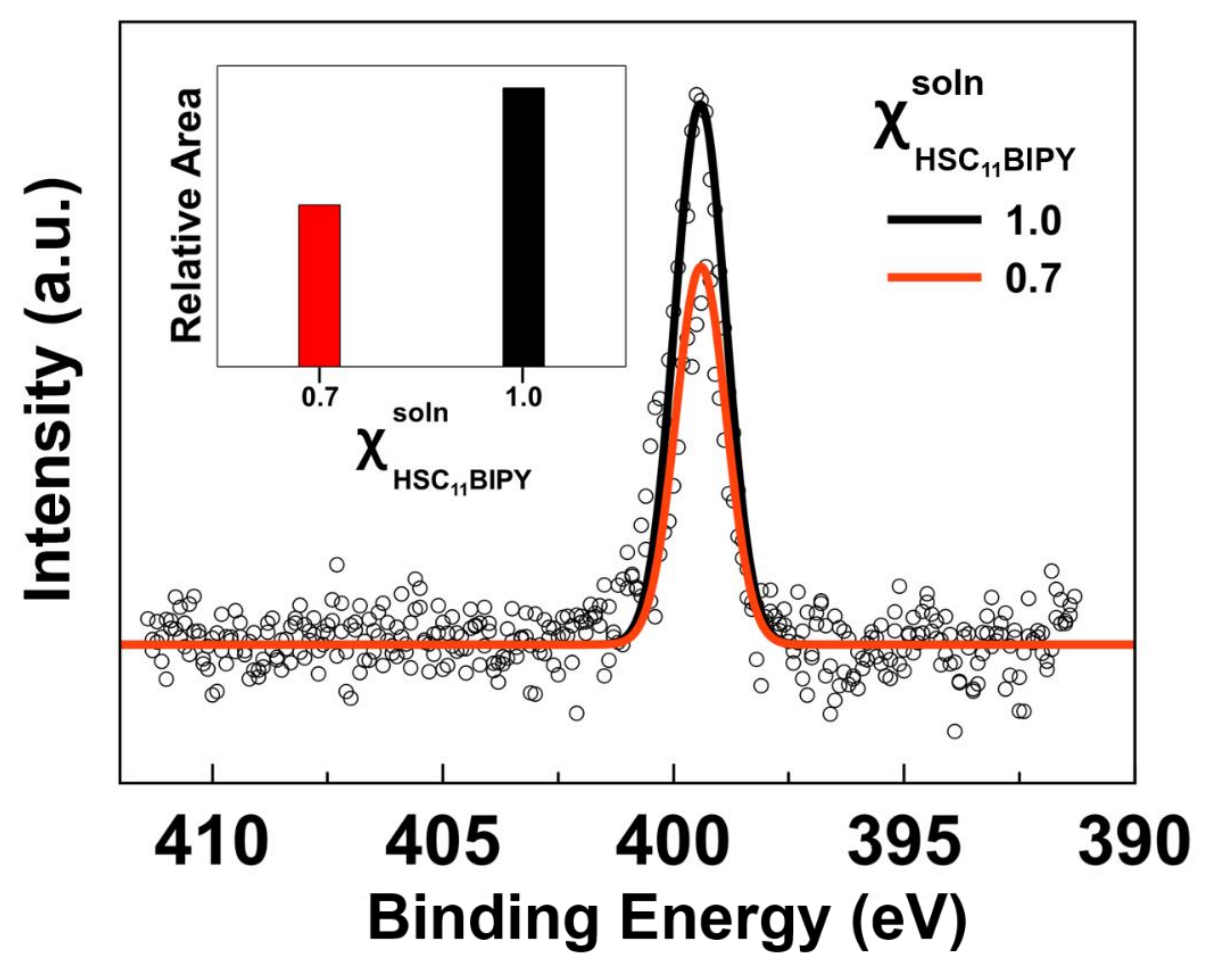


Table S1. Relationship between mole fractions of $\operatorname{HSC}_{n}(n=8,10$, or 18$)$ in solution $\left(\chi_{\mathrm{HSCn}}^{\mathrm{soln}}\right)$ and $\mathrm{SC}_{\mathrm{n}}$ on $\mathrm{Au}^{\mathrm{TS}}$ surface $\left(\chi_{\mathrm{SCn}}^{\text {surf }}\right)$ for constructing mixed SAMs of $\mathrm{SC}_{11} \mathrm{BIPY}$ and $\mathrm{SC}_{\mathrm{n}}$.

\begin{tabular}{cl|cc|cc}
\hline$\chi_{\mathrm{HSC} 18}^{\text {Soln }}$ & $\chi_{\mathrm{SC} 18}^{\text {surf }}$ & $\chi_{\mathrm{HSC10}}^{\text {soln }}$ & $\chi_{\mathrm{SC} 10}^{\text {surf }}$ & $\chi_{\mathrm{HSC} 8}^{\text {soln }}$ & $\chi_{\mathrm{SC} 8}^{\text {surf }}$ \\
\hline 1.0 & $1.00 \pm 0.02$ & 1.0 & $1.00 \pm 0.02$ & 1.0 & $1.00 \pm 0.02$ \\
0.3 & $0.71 \pm 0.05$ & 0.3 & $0.31 \pm 0.01$ & 0.3 & $0.37 \pm 0.09$ \\
0.1 & $0.28 \pm 0.14$ & - & - & - & - \\
\hline
\end{tabular}


Figure S7. Data of static (a,c,e) and dynamic (b,d,f) contact angle measurements for $\mathrm{SC}_{11}$ BIPY SAMs diluted with short $\left(\mathrm{SC}_{8}, \mathrm{SC}_{10}\right)$ and long $\left(\mathrm{SC}_{18}\right)$ diluents on $\mathrm{Au}^{\mathrm{TS}}$. The data points were averaged from ten measurements on separate locations.
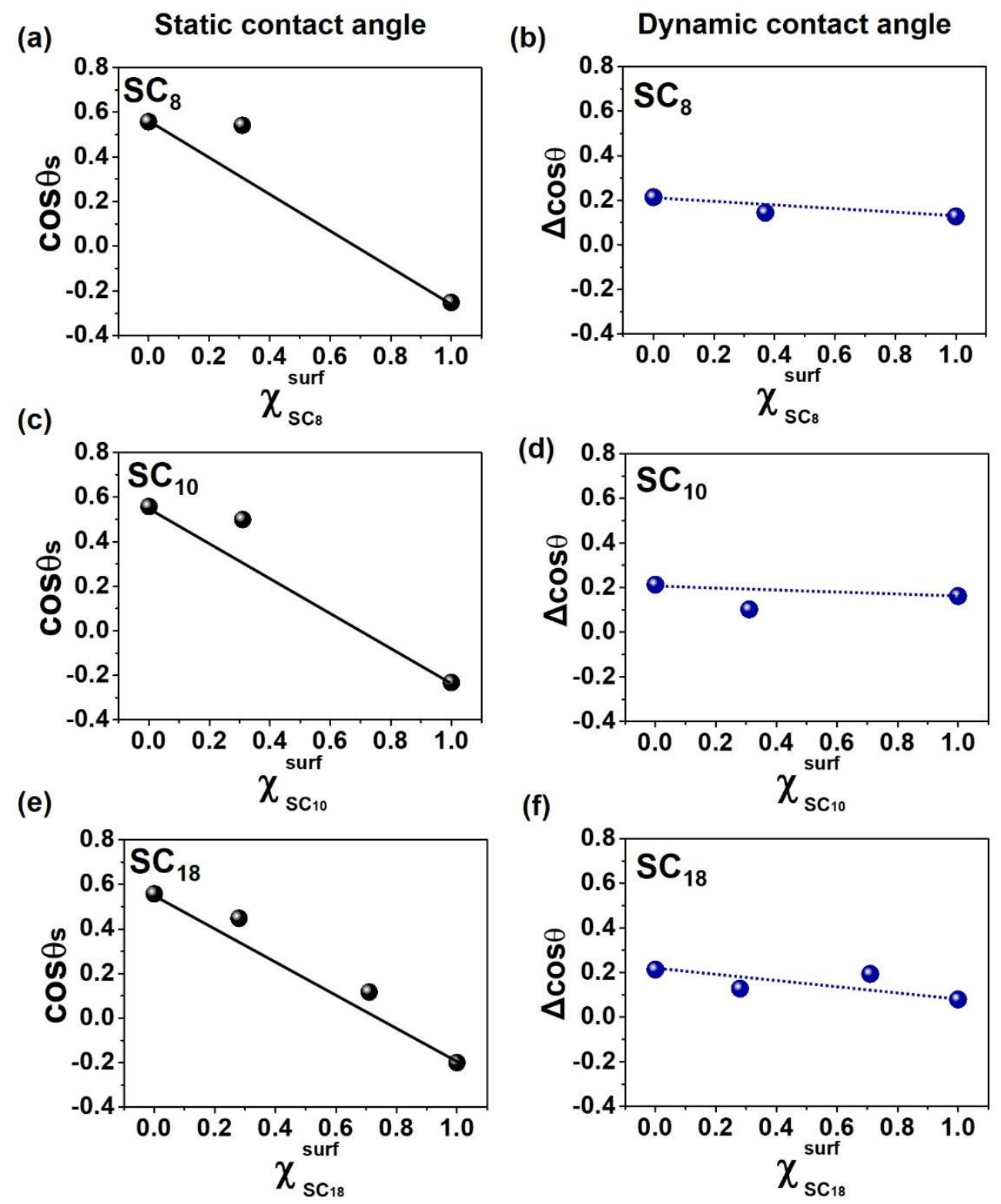
Table S2. Summary of electrical characterization for a series of single-component and binary mixed SAMs formed with $\mathrm{SC}_{11} \mathrm{BIPY}$ and $\mathrm{SC}_{\mathrm{n}}$ $(\mathrm{n}=8,10$, or 18$)$ on $\mathrm{Au}^{\mathrm{TS}}$.

\begin{tabular}{|c|c|c|c|c|c|}
\hline $\begin{array}{l}\text { Ratio of Mixed SAM } \\
\text { on surface }\left(\chi_{\mathbf{S C n}}^{\text {surf }}\right)\end{array}$ & $\begin{array}{l}\text { Number of } \\
\text { junctions }\end{array}$ & $\begin{array}{l}\text { Number of } J-V \\
\text { traces }\end{array}$ & $\begin{array}{l}\log |J(+1.0 \mathrm{~V})|_{\text {mean }} \pm \sigma_{\log |J|} \\
\quad\left(\log |J(+1.0 \mathrm{~V})|_{\text {median }}\right)\end{array}$ & $\begin{array}{l}\log |J(-1.0 \mathrm{~V})|_{\text {mean }} \pm \sigma_{\log |J|} \\
\quad\left(\log |J(-1.0 \mathrm{~V})|_{\text {median }}\right)\end{array}$ & $\begin{array}{c}\log \left|r^{+}\right|_{\text {mean }} \pm \sigma_{\log \mid r+1} \\
\left(\left|r^{+}\right|_{\text {mean }} \pm \sigma_{|r+|}\right)\end{array}$ \\
\hline $\begin{array}{l}\mathrm{SC}_{11} \mathrm{BIPY}: \mathrm{SC}_{18} \\
\quad=1.0: 0.0\end{array}$ & 35 & 1400 & $\begin{array}{c}-0.11 \pm 0.40 \\
(-0.10)\end{array}$ & $\begin{array}{c}-2.26 \pm 0.41 \\
(-2.30)\end{array}$ & $\begin{array}{l}2.15 \pm 0.08 \\
(141.0 \pm 1.2)\end{array}$ \\
\hline $\begin{array}{l}\mathrm{SC}_{11} \mathrm{BIPY}: \mathrm{SC}_{18} \\
\quad=0.7: 0.3\end{array}$ & 8 & 320 & $\begin{array}{c}-0.64 \pm 0.43 \\
(-0.70)\end{array}$ & $\begin{array}{c}-2.68 \pm 0.50 \\
(-2.90)\end{array}$ & $\begin{array}{l}2.11 \pm 0.11 \\
(129.0 \pm 1.3)\end{array}$ \\
\hline $\begin{array}{l}\mathrm{SC}_{11} \mathrm{BIPY}: \mathrm{SC}_{18} \\
\quad=0.3: 0.7\end{array}$ & 8 & 320 & $\begin{array}{l}-1.42 \pm 0.58 \\
\quad(-1.50)\end{array}$ & $\begin{array}{c}-3.22 \pm 0.53 \\
(-3.30)\end{array}$ & $\begin{array}{l}1.75 \pm 0.28 \\
(56.0 \pm 1.9)\end{array}$ \\
\hline $\begin{array}{l}\mathrm{SC}_{11} \mathrm{BIPY}: \mathrm{SC}_{10} \\
\quad=0.7: 0.3\end{array}$ & 8 & 320 & $\begin{array}{c}-0.16 \pm 0.53 \\
\quad(-0.20)\end{array}$ & $\begin{array}{c}-2.12 \pm 0.48 \\
(-2.10)\end{array}$ & $\begin{array}{l}1.93 \pm 0.12 \\
(85.0 \pm 1.3)\end{array}$ \\
\hline $\begin{array}{l}\mathrm{SC}_{11} \mathrm{BIPY}: \mathrm{SC}_{8} \\
\quad=0.7: 0.3\end{array}$ & 17 & 680 & $\begin{array}{c}-0.44 \pm 0.53 \\
\quad(-0.50)\end{array}$ & $\begin{array}{c}-2.49 \pm 0.54 \\
(-2.30)\end{array}$ & $\begin{array}{l}1.98 \pm 0.12 \\
(95.0 \pm 1.3)\end{array}$ \\
\hline
\end{tabular}


Table S3. The yields of working junctions for a series of single-component and binary mixed SAMs formed with $\mathrm{SC}_{11} \mathrm{BIPY}$ and $\mathrm{SC}_{\mathrm{n}}(\mathrm{n}=8,10$, or 18$)$ on $\mathrm{Au}^{\mathrm{TS}}$. The mole fractions were determined by XPS.

Ratio of mixed SAM on surface $\left(\chi_{\mathrm{SC} n}^{\mathrm{surf}}\right) \quad$ Yield of working junctions (\%)

\begin{tabular}{|c|c|}
\hline $\begin{array}{c}\mathrm{SC}_{11} \mathrm{BIPY} \mathrm{SC}_{18} \\
=1.0: 0.0\end{array}$ & 75 \\
\hline $\begin{array}{c}\mathrm{SC}_{11} \mathrm{BIPY}: \mathrm{SC}_{18} \\
=0.7: 0.3\end{array}$ & 89 \\
\hline $\begin{array}{c}\mathrm{SC}_{11} \mathrm{BIPY}: \mathrm{SC}_{18} \\
=0.3: 0.7\end{array}$ & 75 \\
\hline $\begin{array}{c}\mathrm{SC}_{11} \mathrm{BIPY}: \mathrm{SC}_{10} \\
=0.7: 0.3\end{array}$ & 80 \\
\hline $\begin{array}{c}\mathrm{SC}_{11} \mathrm{BIPY}: \mathrm{SC}_{8} \\
\quad=0.7: 0.3\end{array}$ & 74 \\
\hline
\end{tabular}


Figure S8. Arrhenius plots $(\ln |J|$ as a function of inverse temperature, $1000 / T)$ of (a) pure $\mathrm{SC}_{11} \mathrm{BIPY}$ SAM and mixed SAMs diluted with (b) $30 \%$ and (c) $70 \% \mathrm{SC}_{18}$ at $+V$ and $-V$.
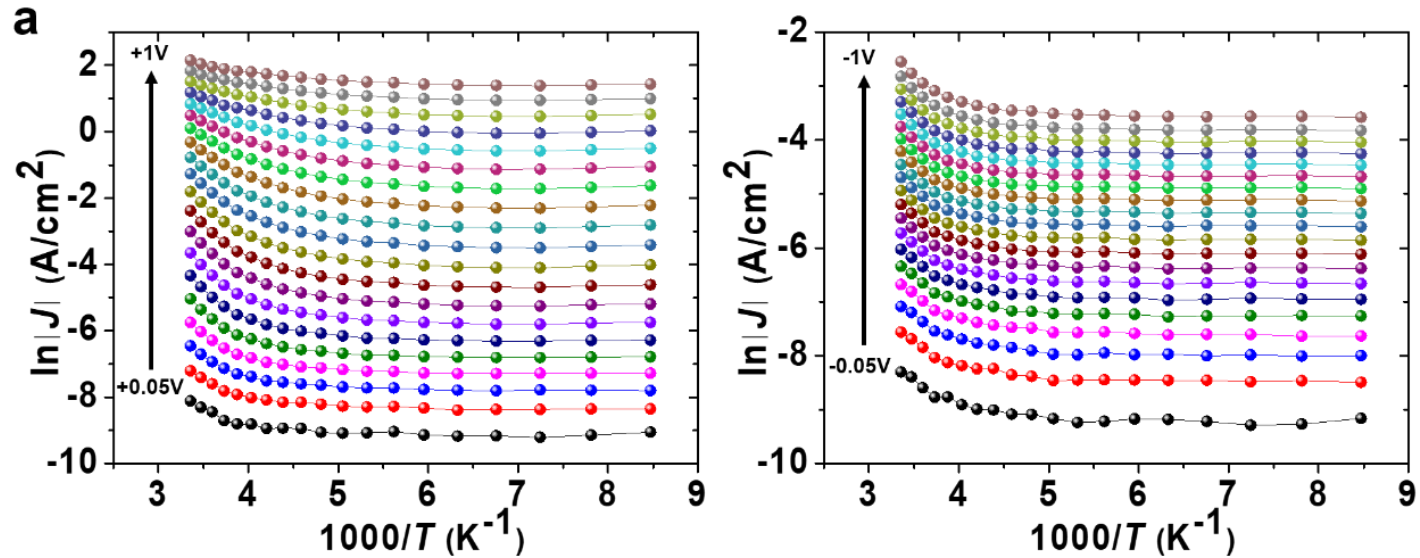

b
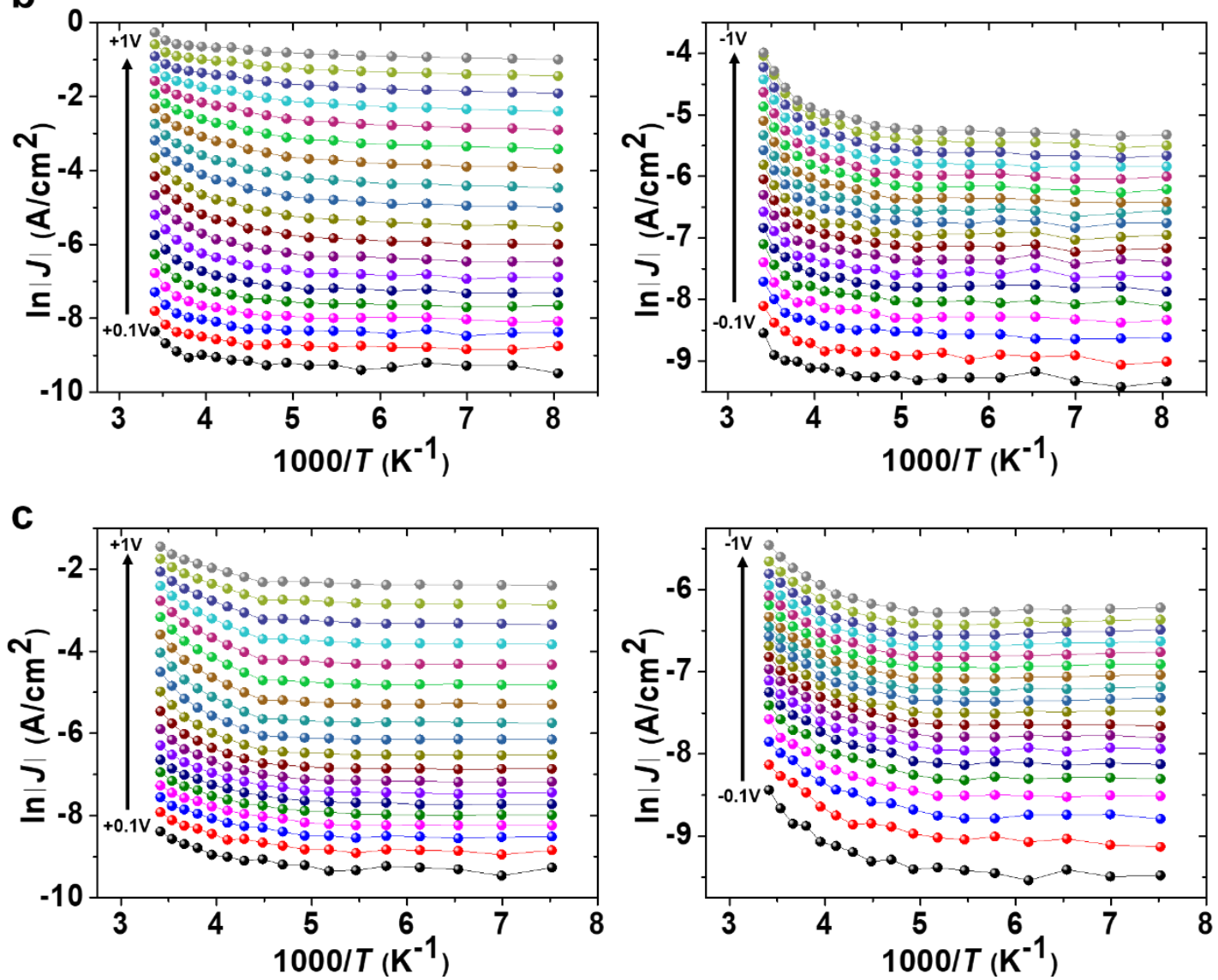
Figure S9. Arrhenius plots $(\ln |J|$ as a function of inverse temperature, $1000 / T)$ of mixed SAMs diluted with (a) $30 \% \mathrm{SC}_{8}$ and (b) $30 \% \mathrm{SC}_{10}$ at $+V$ and $-V$.
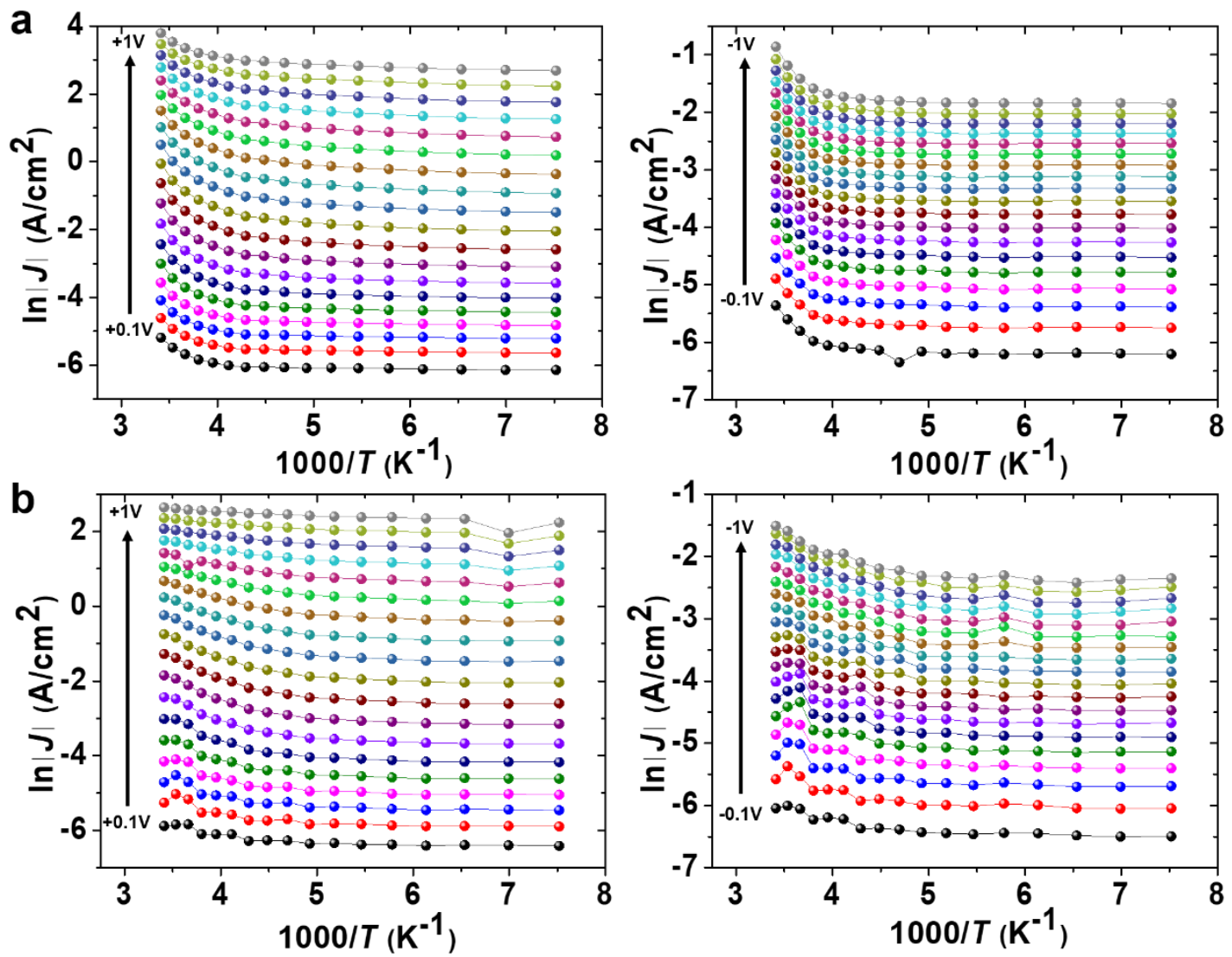
Figure S10. Asymmetric energy diagrams of $\mathrm{Au}^{\mathrm{TS}} / \mathrm{SC}_{11} \mathrm{BIPY} / / \mathrm{Ga}_{2} \mathrm{O}_{3} / \mathrm{EGaIn}$ junction at $-V$ and $+V$, which explains the significant rectification. It was taken from the literature. ${ }^{11}$

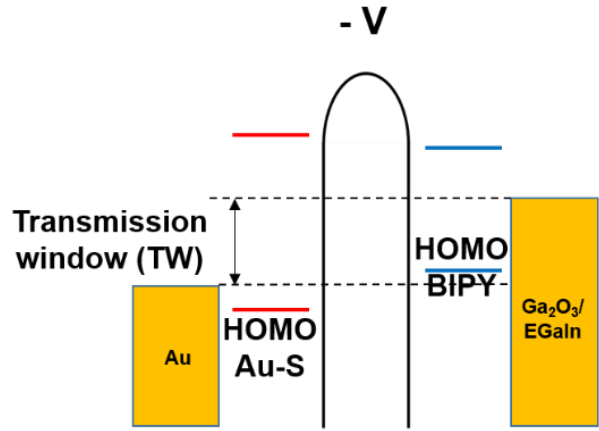

decoupling unit weak orbital gating

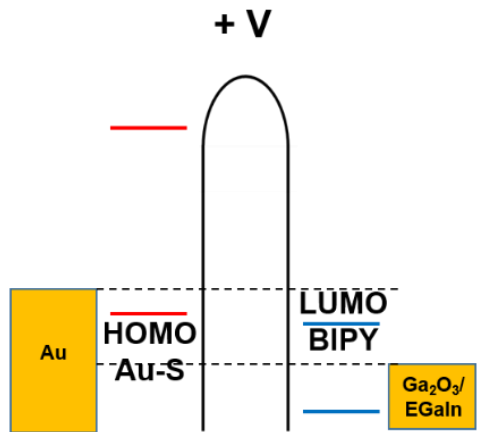

decoupling unit weak orbital gating 
Figure S11. $E_{\text {a }}$ plots against applied external voltage for (a) pure $\mathrm{SC}_{11} \mathrm{BIPY} \mathrm{SAM}$ and mixed SAMs diluted with (b) $30 \%$ and (c) $70 \% \mathrm{SC}_{18}$ at $+V$ and $-V$.

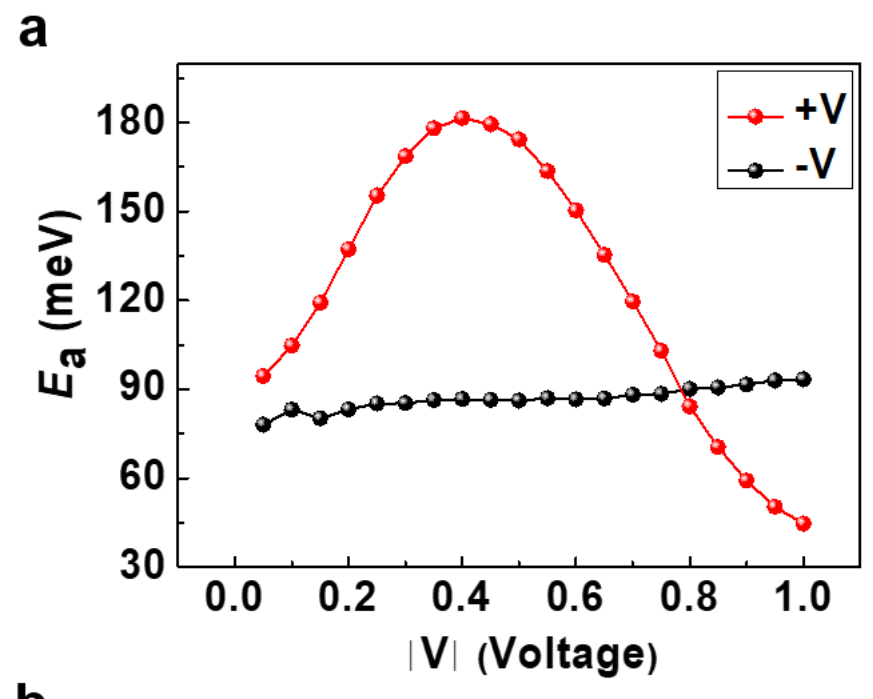

b
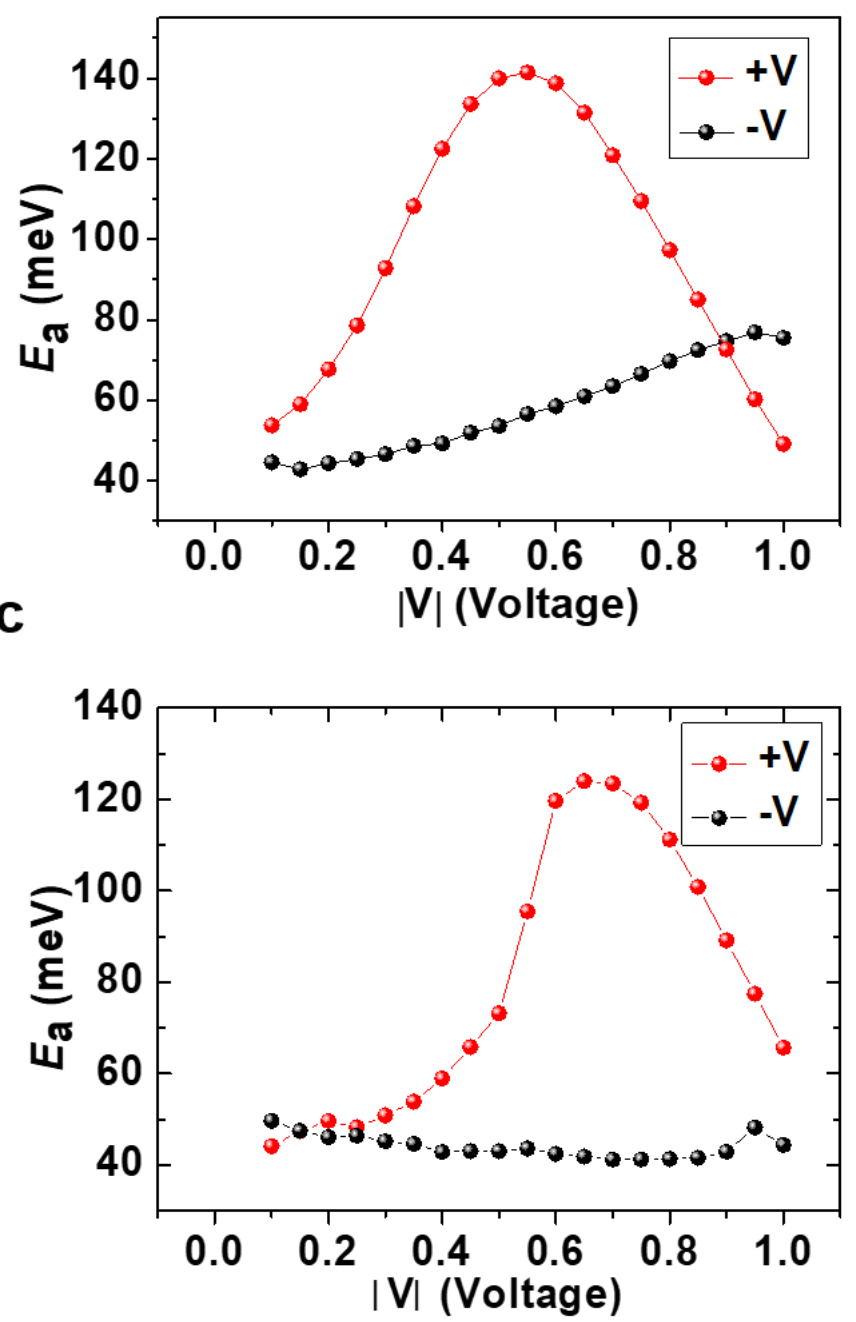
Figure S12. $E_{\text {a }}$ plots against applied external voltage for $\mathrm{SC}_{11} \mathrm{BIPY}$ SAMs diluted with (a) $30 \%$ $\mathrm{SC}_{8}$ and (b) $30 \% \mathrm{SC}_{10}$ at $+V$ and $-V$.

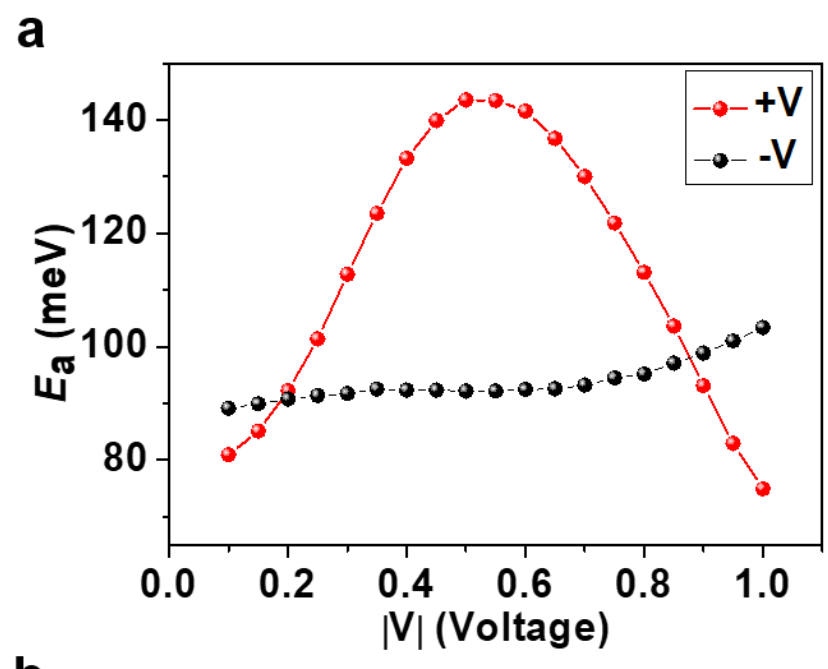

b

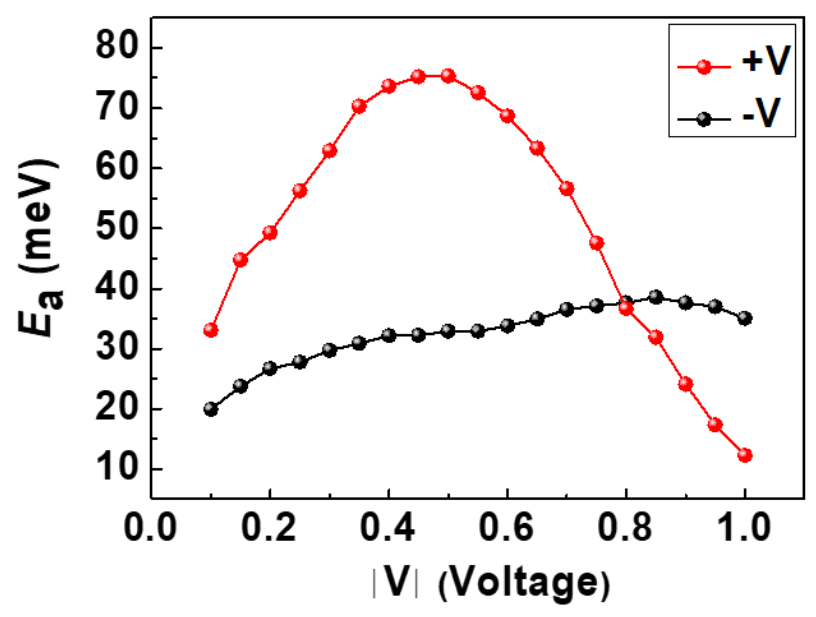




\section{References}

1. Yoon, H. J.; Liao, K.-C.; Lockett, M. R.; Kwok, S. W.; Baghbanzadeh, M.;

Whitesides, G. M. Rectification in tunneling junctions: 2,2'-bipyridyl-terminated $n$ alkanethiolates. J. Am. Chem. Soc. 2014, 136, 17155-17162.

2. Kong, G. D.; Kim, M.; Cho, S. J.; Yoon, H. J. Gradients of rectification: Tuning molecular electronic devices by the controlled use of different-sized diluents in heterogeneous self-assembled monolayers. Angew. Chem. Int. Ed. 2016, 55, 10307-10311. 3. Kong, G. D.; Jin, J.; Thuo, M.; Song, H.; Joung, J. F.; Park, S.; Yoon, H. J. Elucidating the role of molecule-electrode interfacial defects in charge tunneling characteristics of large-area junctions. J. Am. Chem. Soc. 2018, 140, 12303-12307.

4. Byeon, S. E.; Kim, M.; Yoon, H. J. Maskless arbitrary writing of molecular tunnel junctions. ACS Appl. Mater. Interfaces 2017, 9, 40556-40563.

5. Chiechi, R. C.; Weiss, E. A.; Dickey, M. D.; Whitesides, G. M. Eutectic galliumindium (EGaIn): A moldable liquid metal for electrical characterization of self-assembled monolayers. Angew. Chem. Int. Ed. 2008, 47, 142-144.

6. Kong, G. D.; Yoon, H. J. Influence of Air-Oxidation on Rectification in Thiol-Based Molecular Monolayers. J. Electrochem. Soc. 2016, 163, G115-G121.

7. Nelson, K. E.; Gamble, L.; Jung, L. S.; Boeckl, M. S.; Naeemi, E.; Golledge, S. L.; Sasaki, T.; Castner, D. G.; Campbell, C. T.; Stayton, P. S. Surface Characterization of Mixed Self-Assembled Monolayers Designed for Streptavidin Immobilization. Langmuir 2001, 17, 2807-2816.

8. $\quad$ Rivas, L.; Soares, C. M.; Baptista, A. M.; Simaan, J.; Di Paolo, R. E.; Murgida, D. H.; Hildebrandt, P. Electric-Field-Induced Redox Potential Shifts of Tetraheme Cytochromes 
c3 Immobilized on Self-Assembled Monolayers: Surface-Enhanced Resonance Raman Spectroscopy and Simulation Studies. Biophys. J. 2005, 88, 4188-4199.

9. Tokel-Takvoryan, N. E.; Hemingway, R. E.; Bard, A. J. Electrogenerated chemiluminescence. XIII. Electrochemical and electrogenerated chemiluminescence studies of ruthenium chelates. J. Am. Chem. Soc. 1973, 95, 6582-6589.

10. Cassie, A. B. D.; Baxter, S. Wettability of porous surfaces. Trans. Faraday Soc. 1944, 40, 0546-0550.

11. Kang, H.; Kong, G. D.; Byeon, S. E.; Yang, S.; Kim, J. W.; Yoon, H. J. Interplay of Fermi Level pinning, Marcus inverted transport and orbital gating in molecular tunneling junctions. J. Phy. Chem. Lett. 2020, 11, 8597-8603. 